\title{
UREA CLEARANCE AND DIURESIS IN MAN
}

\author{
By RAFAEL DOMINGUEZ AND ELIZABETH POMERENE \\ (From the Division of Laboratories, Department of Pathology, St. Luke's Hospital, Cleveland)
}

(Received for publication May 18, 1942)

The ratio of the rate of excretion of urea to the concentration of urea in the plasma, that is, the urea clearance, has been known for many years to increase with the flow of urine (1). The quantative relation between the urea clearance and urine flow has been represented by numerous equations, each adequate for restricted ranges of urine flow. The most common of these equations, in this country, at least, have been summarized in Table $I$.

However, there is no justification for these multiple equations, except, perhaps, their simplicity and the ease with which their constants can be computed. Actually, when the clearances are plotted on a diagram, the trend indicated by the points follows a continuous curve, without angles or kinks. Therefore the relation between the clearance and urine flow should be represented, mathematically, by a continuous function of the urine flow, with a continuously turning tangent from the beginning to the end. The curve of the clearances resulting from the equations given in Table I does not have this property, since the slope of the curve at the end of one restricted range of diuresis is not equal to the slope of the curve at the beginning of the next. Thus, in passing from the first straight line (Equation 1, Table I) to the square root curve (Equation 2, Table I), the slope changes abruptly at $\mathrm{v}=0.35 \mathrm{cc}$. per minute, just as it changes also abruptly at $\mathrm{v}=2$ in passing from the square root curve (Equation 2,
Table I) to the other segment of straight line (Equation 3, Table I). Besides, since the constants given by these equations do not all have the dimensions of a clearance, it is confusing to call them clearances. And if, in order to overcome this difficulty, the first constant is ignored and the remaining two are interpreted as ordinates at selected urine flows, this method transforms the whole curve into two discontinuous clusters of points, one at $1 \mathrm{cc}$. per minute, the other at $2 \mathrm{cc}$. per minute.

To these difficulties we may add that Equations 2 and 3 break down altogether in some forms of renal disease-nitrogen retention phase of prostatic obstruction (4)-and in other cases that we shall present here. It is not profitable to increase the number of equations to suit every new case.

This paper will deal with an analysis of the data on the excretion of urea in 4 subjects, 1 normal and 3 nephrosclerotics, data which cover a wide range of excretory function. From this analysis, we shall develop an equation that overcomes the inherent defects in multiple representations. With the help of this equation, we shall be able to follow the changes in the clearance curve in renal disease, and to discuss the concentration ratio of urea.

After presenting the data, we shall therefore consider, specifically, (1) the representation of the data on urea clearance, at all urine flows, by

TABLE I

Equations representing the urea clearance at various ranges of diuresis

\begin{tabular}{|c|c|c|c|c|}
\hline Range of urine flow & Equation & Designation of constant & Dimensions of constant & Geometrical interpretation of constant \\
\hline $\begin{array}{c}c c . \text { per minute } \\
0<\mathrm{v}<0.35\end{array}$ & 1. $C=p v$ & p, minimal clearance $(2)$ & pure number & Slope in $(C, v)$ coordinates \\
\hline $0.35<v<2.00$ & 2. $C=s \sqrt{v}$ & s, standard clearance (3) & square root of flow & $\begin{array}{l}\text { Slope in }(C, \sqrt{v}) \text { coordinates or } \\
\text { ordinate at } v=1 \text { in either }(C, v) \\
\text { or }(C, \sqrt{v}) \text { coordinates }\end{array}$ \\
\hline $2.00<v$ & 3. $C=m$ & m, maximum clearance $(3)$ & flow & $\begin{array}{l}\text { Ordinate at any } v>2.00 \text { in either } \\
(C, v) \text { or }(C, \sqrt{v}) \text { coordinates }\end{array}$ \\
\hline
\end{tabular}

In this table, $\mathrm{C}$ represents the clearance and $\mathrm{v}$ represents urine flow. Both $\mathrm{C}$ and $\mathrm{v}$ have the dimensions of flow. 
a single equation; (2) the rejection of the concept of a maximum clearance; (3) the changes in the constants of the single equation in renal disease; (4) an objection to the current method of expressing the clearance of a renal patient in per cent of a normal clearance; (5) the concentration ratio of urea, its continuous dependence on urine flow, and its equivalence to the clearance at all urine flows; (6) the value of the limiting concentration ratio, as the urine flow approaches zero, in estimates of renal function; (7) the fallacy of comparing the specific gravity of the urine at small urine flows with the urea clearance at any urine flow; and (8) certain a priori considerations that suggest why the clearance of urea and the clearance of other substances should rise with increasing urine flows.

\section{EXPERIMENTAL DATA}

The cases can be briefly summarized as follows: Case 1, a 26-year-old, white woman with normal renal function; Case 2, a 38-year-old, white woman with advanced nephrosclerosis, who died shortly after the experiment; Case 3, a 45-year-old, white woman with hypertension, in whom a renal denervation was done according to the technique of Peet (5) ; and Case 4, a 44-year-old, white man with progressive nephrosclerosis, in whom a bilateral perivascular sympathectomy of the renal pedicle was done. Cases 3 and 4 are part of a separate investigation of the renal excretory function of hypertensive subjects, both before and after renal denervation. The complete data of these cases will be presented in another publication. For this paper, we have selected, in Case 3, two experiments, 1 and 2 years, respectively, after denervation, and in Case 4, one experiment, 21 months after denervation. 1

The data were obtained in the course of experiments in which not only the excretion of urea, but also the excretion of exogenous creatinine, and, in one case, the excretion of xylose, were investigated. In this paper; only the data on urea excretion will be presented.

The rate of excretion of urea and the plasma concentration of urea were followed in each experiment for 8 to 10 consecutive hours. The blood samples and the urine were obtained at intervals of about 1 hour each, but when diuresis was large the interval of urine collection was naturally shortened. The urea was analyzed by the aeration method of Van Slyke and Cullen (6).

In order to save space, the data are presented graph-

1 The surgical operation of Case 3 was performed by Dr. Spencer Braden, Visitant Surgeon in charge of Neurosurgery at St. Luke's Hospital, and that of Case 4 by Dr. Carl H. Lenhart, Professor of Surgery of the School of Medicine, Western Reserve University, then Director of the Surgical Division of St. Luke's Hospital. ically in Figures 1 and 2, where the cases are identified by means of subscripts. The urea nitrogen concentration of the urine $(u)$ and the urea nitrogen concentration in the plasma (x) were calculated in $\mathrm{mgm}$. per cc. of urine and plasma, respectively. The urine flow, or diuresis, ( $v)$ is given in cc. per minute. The rate of excretion $(y)$ is obtained by multiplying $u$ and $v$. The mean rate of excretion ( $y$ ), in $\mathrm{mgm}$. per minute, is assumed to occur at the middle of the interval of urine collection. The plasma concentration corresponding to the middle of this interval $(x)$ is obtained by graphic linear interpolation in a diagram in which the plasma concentration is plotted against the time. With these symbols, the urea clearance $(C)$ is given by the ratio $y / x$ in cc. per minute.

As can be seen in Figures 1 and 2, the trend in the clearance in all the 4 cases is always upward, before as well as after a urine flow of 2 cc. per minute, the socalled augmentation limit of Möller, McIntosh and Van Slyke (3). The initial rise is quite steep in Cases 1 and 3 , low in Case 4, and very low in Case 2. At no point is the clearance (the mean clearance) independent of diuresis, so that the clearance at a given time cannot be completely defined unless the urine flow at that time is also specified.

\section{SINGLE EQUATION}

An equation previously proposed (7)

$$
\mathrm{C}=\mathrm{A}\left(1-\mathrm{e}^{-\mathrm{kv}}\right), \quad \text { Equation } 4
$$

in which $A$ and $k$ are constants and $e$ is the base of the natural logarithms, has been shown to fit, at ordinary diuresis, a large set of data $(3,8)$ better than Equation 2, Table I.

At very low diuresis, it reduces to

$$
\mathrm{C}=\mathrm{Ak} \cdot \mathrm{v}, \quad \text { Equation } 5
$$

as can be seen by expanding the right hand side of Equation 4 in powers of $\mathrm{v}$ and retaining only the terms to the first power. Equation 4 contains the 3 equations of Table $I$, as has been recognized by Van Slyke (9). In point of history, it anticipated the experimental data of Chesley (2). But Equation 4, developed as it was for data in which the clearance could be assumed constant at a diuresis beyond 2 cc. per minute, will not satisfy our present data.

However, if we add to it a linear term in diuresis, bv, thus,

$$
\mathrm{C}=\mathrm{A}\left(1-\mathrm{e}^{-\mathrm{kv}}\right)+\mathrm{bv}, \quad \text { Equation } 6
$$

we will get an expression that, at large diuresis, becomes asymptotically equal to the straight line,

$$
\mathrm{C}=\mathrm{A}+\mathrm{bv} . \quad \text { Equation } 7
$$


The curve represented by Equation 6 has a continuously turning tangent, since, from the equation of its first derivative,

$$
\frac{\mathrm{dC}}{\mathrm{dv}}=A \mathrm{ke} \mathrm{e}^{-\mathbf{k v}}+\mathrm{b},
$$

the slope of the tangent diminishes continuously from the finite value $\mathrm{Ak}+\mathrm{b}$ at zero diuresis to the constant value $b$ at large diuresis. Likewise, the proportionality of the clearance to diuresis, at small diuresis, is preserved, since Equation 6 reduces to the equation

$$
\mathrm{C}=(\mathrm{Ak}+\mathrm{b}) \mathrm{v}, \quad \text { Equation } 8
$$

at very low diuresis. Incidentally, the coefficient $(\mathrm{Ak}+\mathrm{b})$, Equation 8, which represents the slope of the clearance curve at zero diuresis, will be shown, later in the paper, to be equal to the limiting concentration ratio of urea.

\section{APPLICATION AND RESULTS}

Equation 6 was applied to our data as follows: first, the linear part (Equation 7) was fitted by least squares to all data at $v$ equal to or larger than $2 \mathrm{cc}$. per minute; then, using the values of $A$ and $b$ thus determined, rearranging Equation 6, and taking the logarithms, we computed a mean value of $\mathbf{k}$ from the equation

$$
-\mathrm{k} \cdot \log \mathrm{e}=\frac{1}{\mathrm{v}} \log \frac{\mathrm{A}+\mathrm{bv}-\mathrm{C}}{\mathrm{A}} .
$$

In this equation $C$ and $v$ either assume the values of the clearance at $\mathrm{v}$ less than $2 \mathrm{cc}$. per minute and their respective urine flows, or represent means of conveniently grouped data. For the purpose of this paper, no further refinement in fitting was considered necessary. The results are shown in Figures 1 and 2.

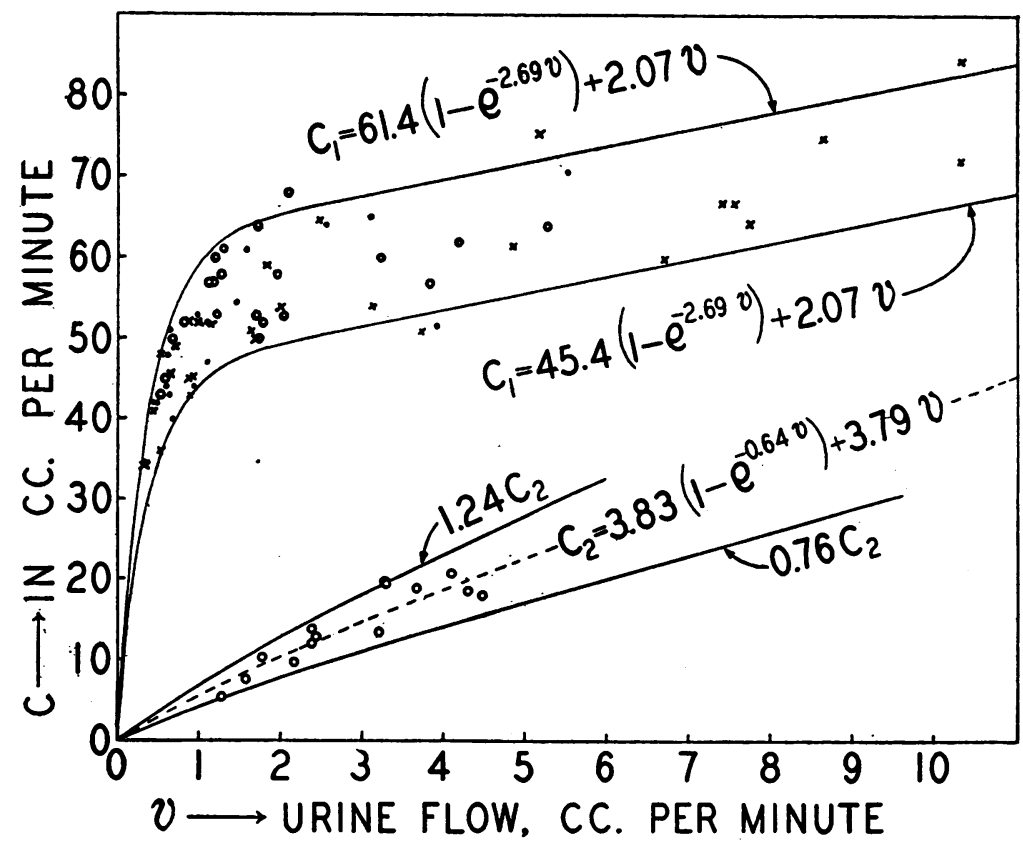

Fig. 1. Urea Clearance C of a Normal Subject ( $C_{1}$ ) and of a NEPHROSCLEROTIC $\left(C_{2}\right)$

The equation for the grouped data of Case 1 is $C_{1}=53.4\left(1-e^{-2.69} v\right)+$ $2.07 \mathrm{v}$. The points represent endogenous urea data in oral creatinine experiments; the open circles represent urea data following urea and creatinine ingestion; and the crosses represent endogenous urea data in oral xylose experiments. The two curves $C_{1}$, obtained by changing $A$ by \pm 15 per cent of its mean value, inclose all but 6 of the 68 observations. The open circles of Case 2 represent endogenous urea data obtained during an experiment with ingested creatinine. As shown by the solid curves, a 24 per cent variation of the mean clearance $C_{2}$ is needed to include 13 of the 14 observations. 


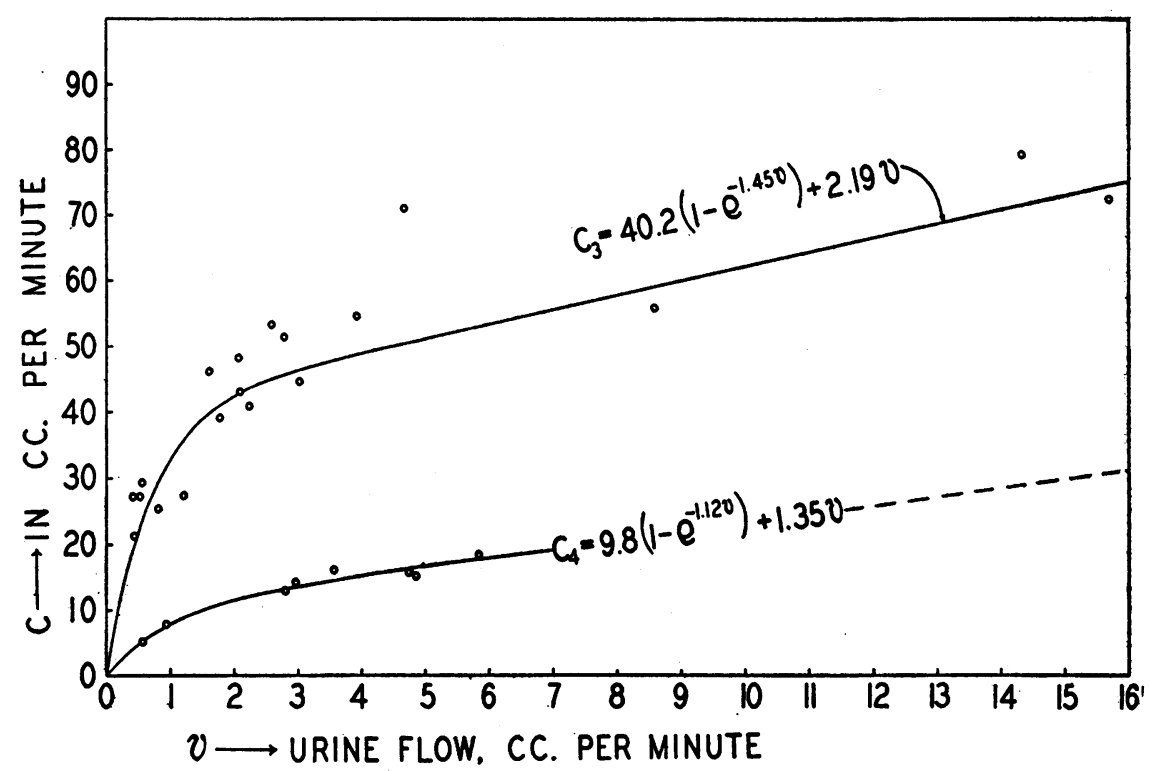

Fig. 2. Urea Clearance (C) of 2 Nephrosclerotics, One ( $C_{8}$ ) After Splanchnicectomy and Another $\left(C_{4}\right.$ ) After Denervation of the Renal Pedicles

The curve $C_{3}$ represents the mean curve for all the data (51 observations) on this subject. The mean position of the points shown is somewhat higher than the mean curve $\mathrm{C}_{8}$. The erratic point at $\mathrm{v}=4.7 \mathrm{cc}$. per minute corresponds to a period of sudden increase in urine flow after a long interval of decreasing urine flows. In this subject, a 34 per cent variation of the mean value of $A, 40.2$, has to be allowed in order to include 90 per cent of the observations.

The mean values of the constants $A, k, b$, and the standard error of $\mathrm{b}$, are: Case $1, \mathrm{~A}=53.4$, $\mathrm{k}=2.69, \mathrm{~b}=2.07$ (standard error 0.548); Case $2, \mathrm{~A}=3.83, \mathrm{k}=0.64, \mathrm{~b}=3.79$ (standard error 0.586); Case 3, $\mathrm{A}=40.2, \mathrm{k}=1.45, \mathrm{~b}=2.19$ (standard error 0.432); and Case 4, $\mathrm{A}=9.8$, $\mathrm{k}=1.12, \mathrm{~b}=1.35$ (standard error 0.435). By comparing $\mathrm{b}$ with its standard error, and by taking into consideration the number of observations, it will be seen that the slope $b$ is in each instance significantly different from zero.

This result in the normal subject, Case 1, is contrary to the experimental evidence of Möller, McIntosh and Van Slyke (3) in 6 normal subjects, but is in agreement with the experimental data of Chasis and Smith (10) in 9 normal subjects, although Chasis and Smith interpreted their results differently. ${ }^{2}$ Our results in nephrosclerosis, Cases

2 Chasis and Smith describe the urea clearances illustrated by them as follows [(10) page 350]: "Inspection of the absolute urea clearance, as portrayed in Figures 1 and 2, shows that there is a progressive increase in the urea clearance as the urine flow increases from low to
2, 3, and 4, and the results of Hayman, Longley and Bobey (4) in prostatic obstruction, together with the results in our normal subject and with the interpretation we give to the data of Chasis and Smith in normal subjects, show that the concept of a maximum clearance does not have the generality that we have been so far led to believe.

The trend and scatter of the points in our cases require a few comments. In Case 1 , the scatter of the points is quite large, but at flows larger than $2 \mathrm{cc}$. per minute the points seem to lie within a

high value." These authors did not determine the mean slope of the linear part of their data, but by means of a stretched thread we estimate these slopes to be 1.14 for their Figure 1 and 1.5 for their Figure 2. Seeing that the scatter of their points is less than in our normal subject, Case 1, and that the range of urine flows is larger, we hazard the suggestion that, had their data been subjected to statistical treatment, the slope of their data at large diuresis would have proved significantly different from zero. That Chasis and Smith, however, did not believe this to be the case, is evident from their statement [ (10) page 357] : "Inspection of Figures 1 and 2 shows that our data conform roughly to the 'standard' and 'maximum' clearance concept of Möller, McIntosh and Van Slyke." 
zone bounded by parallel lines, as if most of the variation could be charged to $A$ rather than to $b$. $B y$ adding to $A, \pm 15$ per cent of its mean value, 53.4, we get the two lines shown, inclosing 91 per cent of the points (Figure 1).

In Case 2, the trend of the observations is well represented by the curve $\mathrm{C}_{2}$, Figure 1 . Although the absolute variation is smaller than in Case 1, the relative variation is larger. In fact, in order to inclose practically all the data, it was found necessary to vary $C_{2}$ by 24 per cent. But, since $A$ and $b$ have about the same numerical magnitude, we cannot lay all the variation on $\mathrm{A}$.

In Case 3 the scatter of the data is very great. Although a detailed account of the data on this case will be published later, it may now be said that the curve $\mathrm{C}_{3}$ represents the mean curve fitting all the data in this subject. A variation of 34 per cent of the mean value of $A, 40.2$, is necessary to inclose 90 per cent of the observations. The large diureses recorded were neither induced nor controlled by the conditions of the experiments. Had we controlled diuresis, as Chasis and Smith did (10), we would very likely have lessened this scatter. The erratic point at $\mathrm{v}=4.7$ corresponds to a sudden increase in diuresis interrupting a rather long interval of slowly decreasing diuresis.

In Case 4 the scatter is least. Yet, the constant $\mathrm{b}$ in this case, 1.35, is the least well determined, partly because of its small magnitude, partly because of the small number of observations.

It may be of interest to notice that the persistent effect of urine flow on the clearance occurs in both the normal kidney (Case 1) and the arteriosclerotic kidney (Cases 2, 3 and 4), and in the latter not only when the nerve supply of the organ is intact (Case 2), but also when it has been severed (Cases 3 and 4$)$.

\section{EFFECT OF RENAL DISEASE ON THE CONSTANTS}

Comparison of the constants in these cases shows that in renal disease the constants $\mathrm{A}, \mathrm{k}$, and $b$, are not affected to the same extent. For instance, $A_{2}$ is only about 7 per cent of $A_{1}, k_{2}$ about 24 per cent of $k_{1}$, and $b_{2}$ actually larger than $b_{1}$. This unequal effect of disease on the constants is of considerable practical significance. To be sure, the constant A may diminish in all types of renal disease, as is generally known, but $k$ also may diminish, and, when $\mathrm{k}$ does diminish, the shape of the curve is no longer similar, in the mathematical sense, to its former shape, irrespective of any change in $b$. After careful examination of the "atypical clearances" in prostatic obstruction, illustrated by Hayman, Longley and Bobey (4), we believe that all of them could be shown to be particular examples of Equation 6, on a par with the clearances of our nephrosclerotics.

The extreme case of a clearance rising linearly with urine flow can be arrived at theoretically in the following way. If the kidney loses all power to concentrate urea and yet excretes urine, the rate of excretion of urea, $y$, would be

$$
\mathrm{y}=\mathrm{v} \cdot \mathrm{u}=\mathrm{v} \cdot \mathrm{x}
$$

or, since $C=y / x$,

$$
\mathrm{C}=\mathrm{v} \text {. }
$$

In other words, the smallest clearance compatible with a urine flow greater than zero is that in which the clearance is equal to the urine flow itself, and obviously it could not be less than this, except in anuria. This extreme clearance, which is represented by a straight line with slope 1 , can be obtained directly from Equation 6 by making either $A$ or $k$ equal to zero, and $b$ equal to 1 .

\section{CRITICISM OF PER CENT COMPARISON OF UREA CLEARANCES}

By writing out the ratio of two clearances, using for each the form given by Equation 6, we can see that no two clearances can be proportional to each other unless the constant $k$ of one is equal to the constant $k$ of the other, and unless $b$ changes proportionately with $\mathrm{A}$ in one of them or is equal to zero in both. But, we have just shown that in renal disease $\mathrm{k}$ changes, and $\mathrm{b}$ is neither equal to zero nor does it decrease proportionately to $\mathrm{A}$; consequently, the practice of expressing a patient's clearance in per cent of a normal clearance is, in general, not justified. For example, the ratio of the clearances $\left(C_{2} / C_{1}\right)$ at diuresis of $1,2,3$, and $4 \mathrm{cc}$. per minute is, respectively, $0.108,0.181,0.246$, and 0.303 . We cannot conclude from this that the clearance of Case 2 lies somewhere between 11 and 30 per cent of that of Case 1, because this conclusion would be at once vague and misleading. If we say that the clearance of Case 2 is 11 per 
cent of the normal at ordinary diuresis, we ignore the effect of large diuresis. If, on the other hand, we conclude that, at a diuresis of $4 \mathrm{cc}$. per minute, Case 2 will reach a clearance as large as one-third that of the normal, we will shift the emphasis from the impairment of the kidney to the possible beneficial effect of large diuresis.

We must look for another way to compare the degree of renal impairment. The one that presents itself is the limiting concentration ratio of urea, a constant independent of urine flow, as will be shown shortly.

\section{CONCENTRATION RATIO OF UREA}

The concentration ratio is the ratio of the concentration in the urine, $u$, to the concentration in the blood plasma, $\mathbf{x}$. Since the rate of excretion of urea, $y$, is determined by multiplying $v$, the urine flow, by $u$, the urea concentration in the urine, the equation of the concentration ratio can be obtained from that of the clearance by dividing both members of the latter equation by the urine flow. In general, therefore, if the clearance is represented by any given function of diuresis, $\mathrm{C}=\mathrm{f}(\mathrm{v})$, it follows necessarily that

$$
\frac{u}{x}=\frac{u}{x} \cdot \frac{v}{v}=\frac{y}{x} \cdot \frac{1}{v}=\frac{C}{v}=\frac{f(v)}{v}
$$

Conversely, if the concentration ratio $\mathrm{R}$ is known, let us say, $R=\varphi(v)$, then

$$
\frac{\mathrm{y}}{\mathrm{x}}=\frac{\mathrm{u} \cdot \mathrm{v}}{\mathrm{x}}=\mathrm{v} \cdot \mathrm{R}=\mathrm{v} \cdot \varphi(\mathrm{v})
$$

In particular, it follows from Equation 6 that the equation of the concentration ratio is

$$
\frac{\mathrm{u}}{\mathrm{x}}=\frac{\mathrm{A}\left(1-\mathrm{e}^{-\mathrm{kv}}\right)+\mathrm{bv}}{\mathrm{v}} \cdot \text { Equation } 9
$$

Equations 6 and 9 are entirely equivalent and interchangeable. The concentration ratio corresponding to zero diuresis can be determined by calculating the limit reached by the right hand side of Equation 9 as diuresis approaches zero. This limit, $(\mathrm{Ak}+\mathrm{b})$, is numerically equal to the initial slope of the clearance curve (Equation 8). To the zero clearance there corresponds, therefore, the limiting concentration ratio $(A k+b)$. The correspondence between the concentration ratio and the clearance is complete at all diureses. ${ }^{8}$

The behavior of the concentration ratio can be followed in Figure 3. The points were obtained from the original data of Cases 1,2,3 and 4, while the curves are the result of substituting in Equation 9 the already fitted clearances $C_{1}, C_{2}, C_{3}$, and $\mathrm{C}_{4}$.

\section{LIMITING CONCENTRATION RATIO}

Each curve in Figure 3 begins at a definite point, the point we have called the limiting concentration

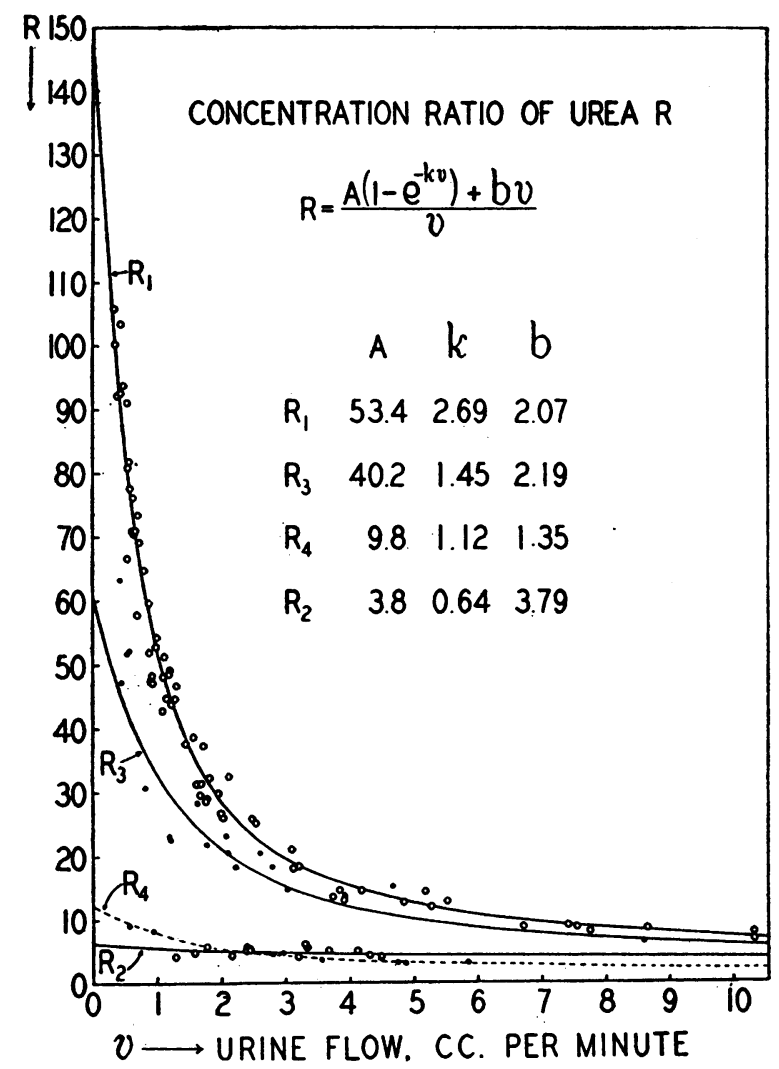

Fig. 3. Concentration Ratio of Urea, R, in a Normal Individual, Case 1, and in 3 Nephrosclerotics, Cases 2, 3 ANd 4.

The cases are identified by the subscripts of $R$. The curves begin at the value $A k+b$, the limiting concentration ratio at $v=0$. The large divergence of the curves at $\mathrm{v}=0$ and their closeness at large diuresis should be noticed. In Case 2 the concentration ratio, $R_{2}$, is almost constant within the range of diureses observed.

\footnotetext{
${ }^{8} U_{p}$ to the present time, the correspondence between these two entities has been considered only at urine flows in the neighborhood of $1 \mathrm{cc}$. per minute, at which flows the concentration ratio is about equal numerically to the clearance (11 to 13$)$.
} 
ratio of urea (7). From this limit on, the concentration ratio lowers quite rapidly in Case 1, reaching, at $\mathbf{v}=10$, a value about 5 per cent of its initial value. In Case 3 , the concentration ratio begins at 60.5 and at $v=10$, has become equal to $6.2,10.3$ per cent of its initial value. In Case 4, the concentration ratio is initially 12.5 , and at $\mathrm{v}=10$, has become $2.5,20$ per cent of the former. In Case 2, the concentration ratio begins at a very low level, 6.2, and, if allowed to extrapolate to $\mathrm{v}=10$, it will become equal to $4.2,67$ per cent of its initial level. At $v=0$, the concentration ratio of Case 1 is 2.4 times that of Case 3, 11.7 times that of Case 4, and 23.4 times that of Case 2 ; at $\mathrm{v}=1$, the concentration ratio of Case 1 is, in the same order, 1.6, 6.6, and 9.3 times that of the others; and at $\mathbf{v}=10$, it is, in the same order, 1.2, 3.0, and 1.8 times that of the others. The really discriminating part of the curves is therefore the part that corresponds to small diuresis, and the smaller the diuresis the better.

This conclusion is quite contrary to the opinion of Chasis and Smith (10), who think it advisable to maintain the urine flow above $1.5 \mathrm{cc}$. per minute when utilizing the excretion of urea as an index of renal function, "since at flows below that level complicating factors (dehydration, lowered filtration rate, etc.) may vitiate any empirical mathematical correction." It is not clear in the paper of Chasis and Smith what part is played by "dehydration, lowered filtration rate, etc." on the effect which a diuresis less than $1.5 \mathrm{cc}$. per minute has on the clearance, or what difference, if any, exists between the effect of these factors in renal disease and in health. Yet, in so far as a comparison between the normal and the abnormal

4 It should be noticed that Equation 2, Table I, does not lead to a definite limit for the concentration ratio (7), while Equation 1, Table I, leads to the constant $u / x=p$, that is, a constant concentration ratio at all diureses below 0.35 cc. per minute. This constancy means, graphically, that the curve of the concentration ratio, growing higher and higher as diuresis diminishes, will bend suddenly at $\mathbf{v}=0.35 \mathrm{cc}$. per minute, and, at smaller diureses, will become parallel to the axis of diuresis. This unlikely result shows that the limiting concentration ratio arrived at by fitting a straight line to the clearance at small diuresis does not give a close approximation to this limit. A closer value may be found by linear extrapolation from the concentration ratios at low diuresis, as can be seen in Figure 3. states of renal function is concerned, it would seem immaterial which the effects of the factors mentioned by Chasis and Smith might be. If they have the same effect on both the normal and the abnormal clearances, the effect will pass undetected, and if they have a different effect, why not make use of it to differentiate further the two cases? Besides, the curves shown in Figures 1, 2 , and 3 are so smooth that no source of trouble appears critically at $1.5 \mathrm{cc}$. per minute or at any other diuresis.

While we do not find any good reason for restricting our observations to urine flows greater than $1.5 \mathrm{cc}$. per minute, a glance at Figure 3 will show that such restriction in diuresis will leave unused one-half or more of the available scale of the concentration ratio.

Consequently, in order to utilize to the fullest extent the information afforded by the great concentrating power of the normal kidney, the urea excretion in renal disease should be compared with the normal at the smallest possible diuresis. For example, the limiting concentration ratio in Case 1 is 145.7, in Case 2 is 6.2. In other words, the damage to the kidneys of this nephrosclerotic woman is such that their power to concentrate urea has been reduced to only four-hundredths of that of our normal subject. This statement should be contrasted with the per cent comparison made earlier in the paper between the clearances of Case 1 and Case 2. According to this comparison, the clearance of Case 2 is, at $1 \mathrm{cc}$. per minute, 11 per cent of that of Case 1, and, at $4 \mathrm{cc}$. per minute, 30 per cent. In view of the almost total loss of the power of the kidneys of Case 2 to concentrate urea, the inadequacy of the information given by the clearance at $4 \mathrm{cc}$. per minute should be apparent.

We feel justified in suggesting the limiting concentration ratio as a most sensitive index of urea excretion.

\section{BEARING OF THE CONCENTRATION RATIO ON CONCENTRATION TESTS}

The foregoing considerations have their counterpart in the concentration tests of renal function. The low and fixed values of the specific gravity of the urine correspond to the lowering and the small variation of the concentration ratio. Indeed, a 
close correlation between these tests has been verified in both moderate and pronounced impairment of renal function (14), but, according to several reports $(14,15)$, the correlation is not strong when the impairment is slight. Because this question has considerable practical importance, we have started a reinvestigation of it. Even though this investigation is not finished, we are prepared to make a few preliminary remarks.

At present, the majority of the usual concentration tests determine the specific gravity of the urine at the smallest possible diuresis, while the clearance is determined at any diuresis, large or small, but rarely at the smallest possible diuresis. In addition, if diuresis is less than $2 \mathrm{cc}$. per minute, the usual practice consists in referring the clearances to the value they would have at $1 \mathrm{cc}$. per minute, by a formula derived from Equation 2, Table I.

Since the specific gravity of the urine depends on diuresis, and since both the clearance and the concentration ratio of urea depend also on diuresis, it does not seem quite correct to compare the specific gravity at a diuresis of, say, $0.2 \mathrm{cc}$. per minute, with the concentration ratio-or its equivalent, the clearance-at $1 \mathrm{cc}$. per minute, or at larger diureses. When this situation is looked at from the standpoint of the concentration ratio, it appears almost self-evident that in order to make a satisfactory comparison both tests should be carried out at the same diuresis.

\section{POSITIVE SLOPE OF THE CLEARANCE AT} LARGE DIURESIS

The examination of the concentration ratio at large urine flow may give us some insight into the significance of the constant $b$. Figure 3 shows that, at large urine flow, the curves become close to one another, and it suggests that, if the urine flow can be made sufficiently large, the curves will become indistinguishable. According to the maximum clearance concept, the concentration ratio could become, at some large value of diuresis, not only equal to, but even less than 1 . According to the new formulation (Equation 6), the concentration ratio becomes, at large diuresis,

$$
\frac{u}{x}=\frac{A+b v}{v}
$$

and this expression approaches the value $b$ as diuresis becomes larger and larger. Since the concentration of urea in the urine should be, at the least, equal to that in the blood, we conclude that $b$ could not be zero and should not be less than 1 . In all the examples given in this paper, $b$ is larger than 1. In Section 3, we have presented a theoretical argument showing that the urea clearance of a kidney which does not concentrate urea should rise linearly with diuresis, with a slope not less than 1. In the examples of Chasis and Smith (10), cited here in Footnote 2, b is larger than 1. In the diagrams of Shannon (16), the slope of the linear part of the urea clearance of the dog is also larger than 1 .

It may not be without interest to notice that the data of Chasis and Smith (10) on the excretion of inulin in man, and those of Shannon (16) on the excretion of creatinine in the dog, show likewise an upward trend in the clearance of these substances as diuresis increases. This evidence suggests that the inference we have drawn from the behavior of the concentration ratio of urea at large diuresis may be generalized to other substances excreted in the urine. ${ }^{5}$

\section{SUMMARY}

The urea clearance in man rises continuously with diuresis at all diureses, both in health and in

\footnotetext{
5 Shannon (16), and Chasis and Smith (10), although acknowledging the variation of the creatinine and inulin clearances with urine flow, have attempted to explain away this variation, by such considerations as hydration, dehydration, etc. These authors determined neither the slope of the linear part of their clearances nor the standard error of the slope. Had Shannon computed this standard error he would have been enabled to estimate the significance of the slope, and to conclude whether the slope of the creatinine clearance in the dog is significantly different from zero or not. However, Shannon states (16) that the creatinine clearance is essentially constant between 0.5 and $4 \mathrm{cc}$. per minute, and brings in support of this statement the fact that the largest increase in the clearance, in per cent of the clearance at $0.5 \mathrm{cc}$. per minute, is very small in comparison with the per cent increase in the urine flow. This method of comparison, which amounts to making the significance of the slope $b$ in $a$ regression equation of the form $y=a+b x$ dependent on the value of $a$, is incorrect. The significance of the slope $b$ does not depend on a. In fact, the formula of the standard error of $b$ does not contain the term a (17).
} 
renal disease. This effect of diuresis occurs in nephrosclerosis, both with intact renal innervation and after denervation.

The relation between the clearance and diuresis is adequately represented by the equation

$$
C=A\left(1-e^{-k v}\right)+b v,
$$

in which $\mathrm{C}$ stands for the clearance, $\mathrm{v}$ for diuresis, $\mathrm{A}, \mathrm{k}$, and $\mathrm{b}$ are constants, and $\mathrm{e}$ is the base of the natural logarithms. This equation has been fitted to the data of 1 normal subject and of 3 patients with nephrosclerosis.

The equation contains as a particular case the approximate proportionality of the normal clearance to diuresis when the latter is less than 0.35 cc. per minute. At diureses between 0.35 and 2 cc. per minute, the equation represents the normal clearance better than the commonly used square root relation. At larger diureses, the equation becomes a straight line with slope b. In the 4 examples given, the constant $b$ is shown to be significantly different from zero.

The existence of the constant $b$ and the diminution in the value of the constant $k$ in renal impairment explain the change in the shape of the clearance curve in renal disease, and render invalid the estimation of the abnormal clearance in per cent of a normal clearance, when the urine flow is not specified.

It is proved that the concentration ratio of urea and the clearance of urea are mutually equivalent at all diureses, and that, if the equation of one of them is known, the equation of the other is known.

The limiting concentration ratio, that is, the limit approached by the ratio of the urea concentration in the urine to the urea concentration in the plasma as the urine flow approaches zero, is computed. This limiting value, equal numerically to the initial slope of the clearance curve, is recommended as a most sensitive index of urea excretion.

By virtue of the correspondence between the clearance and the concentration ratio of urea, it is shown that, when comparing the concentration tests of renal function with the urea clearance, both the specific gravity of the urine and the clearance-or its equivalent, the concentration ratioshould be compared at the same urine flows.

Since the concentration of urea in the urine cannot become less than that of the blood, it is inferred that the concentration ratio at large diuresis should have the limit 1 . Under these conditions, the urea clearance should have at large diuresis a slope greater than zero, and when both the clearance and the urine flow are computed in the same units, the slope should be at least equal to 1 . This conclusion is borne out by the data presented in this paper and by the data of other investigators. The suggestion is made that this conclusion also applies to the clearance of other substances, such as inulin and creatinine.

We wish to acknowledge our indebtedness to Professor Harry Goldblatt, School of Medicine, and Professor Charles Rehor, Cleveland College, both of Western Reserve University, for their careful revision of the manuscript.

\section{BIBLIOGRAPHY}

1. Ambard, L., Rapport entre le taux de l'urée dans le sang et l'élimination de l'urée dans l'urine. Compt. rend. Soc. de biol., 1910, 69, 411.

2. Chesley, L. C., Validity of the calculation of standard urea clearances from low urine volumes. J. Clin. Invest., 1937, 16, 653; Urea excretion at low urine volumes. Calculation of the "minimal" urea clearances. J. Clin. Invest., 1938, 17, 119.

3. Möller, E., McIntosh, J. F., and Van Slyke, D. D., Studies of urea excretion. II. Relationship between urine volume and the rate of urea excretion by normal adults. J. Clin. Invest., 1928, 6, 427.

4. Hayman, J. M., Jr., Longley, L. P., and Bobey, M., Atypical urea clearances. Tr. A. Am. Physicians, 1941, 56, 291.

5. Peet, M. M., Splanchnic section for hypertension: Preliminary report. Univ. Hosp. Bull., Ann Arbor, 1935, 1, 17.

6. Van Slyke, D. D., and Cullen, G. E., The determination of urea by the urease method. J. Biol. Chem., 1916, 24, 117.

7. Dominguez, R., On the renal excretion of urea. Am. J. Physiol., 1935, 112, 529.

8. Austin, J. H., Stillman, E., and Van Slyke, D. D., Factors governing the excretion rate of urea. J. Biol. Chem., 1921, 46, 91.

9. Van Slyke, D. D., Renal mechanisms controlling composition of body fluids. Chem. Rev., 1940, 26, 105.

10. Chasis, H., and Smith, H. W., The excretion of urea in normal man and in subjects with glomerulonephritis. J. Clin. Invest., 1938, 17, 347.

11. Rabinowitch, I. M., Urea tests of renal efficiency. J. Biol. Chem., 1925, 65, 617.

12. Van Slyke, D. D., McIntosh, J. F., Möller, E., Hannon, R. R., and Johnston, C., Studies of urea excretion. VI. Comparison of blood urea clearance 
with certain other measures of renal function. $J$. Clin. Invest., 1930, 8, 357.

13. Peters, J. P., and Van Slyke, D. D., Quantitative Clinical Chemistry. Williams and Wilkins, Baltimore, 1931, Vol. I, p. 363.

14. Alving, A. S., and Van Slyke, D. D., The significance of concentration and dilution tests in Bright's disease. J. Clin. Invest., 1934, 13, 969.
15. Freyberg, R. H., The choice and interpretation of tests of renal efficiency. J. A. M. A., 1935, 105, 1575. 16. Shannon, J. A., Glomerular filtration and urea excretion in relation to urine flow in the dog. Am. J. Physiol., 1936, 117, 206.

17. Fisher, R. A., Statistical Methods for Research Workers. Oliver and Boyd, Edinburgh, 1936, Sixth Edition, section 26, page 137 . 